\title{
Waist:height ratio, waist circumference and metabolic syndrome abnormalities in Colombian schooled adolescents: a multivariate analysis considering located adiposity
}

\author{
Ricardo Antonio Agredo-Zúñiga ${ }^{1,2}$, Cecilia Aguilar-de Plata ${ }^{3,4}$ and Milton Fabian Suárez-Ortegón ${ }^{4,5, *}$ \\ ${ }^{1}$ Research Group into Human Movement and Health, Faculty of Health Sciences, Universidad de San Buenaventura, \\ Cartagena, Colombia \\ ${ }^{2}$ Department of Health Research, FIT Salud Integral para Todos, Cali, Colombia \\ ${ }^{3}$ Department of Physiological Sciences, Universidad del Valle, Cali, Colombia \\ ${ }^{4}$ Nutrition Group, Universidad del Valle, Cali, Colombia \\ ${ }^{5}$ Centre for Population Health Sciences, University of Edinburgh, EH8 $9 A G$ Edinburgh, UK
}

(Submitted 17 September 2014 - Final revision received 15 April 2015 - Accepted 1 June 2015 - First published online 21 July 2015)

Very few large studies in Latin America have evaluated the association between waist:height ratio (W-HtR) and cardiometabolic risk in children and adolescents. Further, multivariable analyses verifying the independence of located subcutaneous fat have not been conducted so far. The aim of this study was to evaluate the associations of W-HtR and waist circumference (WC) with metabolic syndrome abnormalities and high LDL-cholesterol levels in schooled adolescents before and after adjusting for trunk skinfolds and BMI. The sample consisted of 831 boys and 841 girls aged 10-17 years. Biochemical, blood pressure and anthropometrical variables were measured. Age- and sex-specific quartiles of W-HtR and WC were used in Poisson regression models to evaluate the associations. High WC values (highest quartile $v$. quartiles 1-3) were associated with high TAG levels in both sexes (prevalence ratio, boys: 2.57 (95\% CI 1.91, 3.44); girls: 1.92 (95\% CI 1.49, 2.47); $P<0.05$ ), and with high blood pressure specifically in female adolescents $(3.07$ (95\% CI 1.58, 5.98); $P<0.05)$, independently of trunk skinfolds or BMI $(P<0.05)$. Associations of high WC with high fasting glucose (boys), low HDL-cholesterol and having at least two abnormalities did not remain significant in most of the adjustments for trunk skinfolds or BMI $(P>0.05)$. High W-HtR (highest quartile $v$. quartiles 1-3) was only independently associated with high TAG in female adolescents (1.99 (95\% CI 1.55, 2.56); $P<0.05)$. In conclusion, WC showed better association with cardiometabolic risk than W-HtR in the children of this study. This observation does not support W-HtR as a relevant adiposity marker for cardiovascular and metabolic risk in adolescence.

\section{Key words: Waist:height ratio: Cardiovascular risk: Children: Adolescents}

At present, childhood obesity represents a challenge for healthcare providers as it has been widely shown that general and abdominal fat are significantly associated with the development of ischaemic cardiac events ${ }^{(1)}$, type 2 diabetes mellitus in adults ${ }^{(2)}$ and risk prediction of cardiometabolic disease in children and adolescents ${ }^{(3)}$. Obesity is considered as a state of sub-clinical inflammation characterised by the secretion of cytokines that promote atherosclerotic plaque formation and consequent endothelial dysfunction ${ }^{(4)}$. Consequently, it has been necessary to develop diagnostic tools for early detection of obesity in the paediatric population as a public health prevention strategy. BMI and waist circumference (WC) have been widely used as measures to evaluate the impact of obesity on the risk for cardiometabolic diseases in children ${ }^{(5)}$.

There has been a growing interest in the waist:height ratio (W-HtR) as an adiposity index, with two recent meta-analyses showing that W-HtR has a greater predictive ability of cardiovascular and metabolic risk than classic anthropometric indicators $^{(6,7)}$. A W-HtR $\geq 0.50$ has been proposed as the cut-off point for predicting the risk for CVD and diabetes ${ }^{(8)}$. In addition, some authors state that W-HtR can be the most useful clinical tool for the global detection of abdominal obesity and cardiometabolic risk screening in children and adults ${ }^{(9)}$. However, very few large studies have evaluated the association between W-HtR and cardiometabolic risk in children and adolescents in Latin America. Moreover, multivariate analyses verifying whether this association is independent of located subcutaneous fat have not been conducted so far. The aim of the present study was to evaluate the association of W-HtR and WC with metabolic syndrome (MetS) abnormalities and high LDL-cholesterol in schooled adolescents by considering adjustments for trunk skinfolds and also BMI.

Abbreviations: MetS, metabolic syndrome; SS, subscapular skinfold; W-HtR, waist:height ratio; WC, waist circumference.

* Corresponding author: M. F. Suárez-Ortegón, fax + 44131650 6909, email Milton.Suarez@ed.ac.uk 


\section{Methods}

The study's sample consisted of individuals from a crosssectional study, the IFRECNTEC Study (identification of risk factors for adult non-communicable chronic disease in schooled population), conducted in Cali, Colombia ${ }^{(10)}$. The IFRECNTEC Study evaluated a sample of 2807 subjects aged 5-18 years. Our analysis excluded children aged $<10$ years ( $n$ 628), adult individuals ( $\geq 18$ years, $n$ 91) and cases with missing values for the study variables $(n$ 416). The final remaining sample consisted of 1672 adolescents. Informed written consent was obtained from both the parent and the child. The study was reviewed and approved by the Ethics Committee at Universidad del Valle.

Blood was collected via venepuncture after an overnight fast. Concentrations of fasting glucose, total cholesterol, HDLcholesterol and TAG were determined using enzymaticcolorimetric assays. LDL-cholesterol level was estimated using the Friedwald equation ${ }^{(11)}$. Blood pressure was measured using mercury sphygmomanometers with an appropriately sized cuff in a sitting position after $15 \mathrm{~min}$ of rest. Phase I and V (disappearance) Korotkoff sounds were used to identify systolic blood pressure (SBP) and diastolic blood pressure (DBP) ${ }^{(12)}$. Body weight and height were measured using standard techniques and instruments ${ }^{(13)}$. BMI was calculated as weight/ height $^{2(14)}$. WC was measured from the midpoint between the lateral iliac crest and the lowest rib using a flexible steel tape measure ${ }^{(15)}$. W-HtR was calculated as WC divided by height. The subscapular skinfold (SS), abdominal skinfold (AS) and supra-iliac skinfold (SIS) were measured using skinfold calipers in the specific locations ${ }^{(13)}$.

\section{Metabolic syndrome abnormalities and high LDL-cholesterol}

We used the abnormalities of MetS according to the criteria by Cook et al. for paediatrics as follows ${ }^{(16,17)}$ : high levels of TAG as levels $\geq 110 \mathrm{mmol} / 1$, low HDL-cholesterol as levels $\leq 40 \mathrm{mmol} / 1$ and high blood pressure as SBP and/or DBP at or above the 90th percentile for age, sex and height according to the National Heart, Lung, and Blood Institute tables ${ }^{(18)}$. However, for high fasting glucose, we avoided using Cook et al.'s cut-off point of glucose as $\geq 110 \mathrm{mmol} / \mathrm{l}$, as even the current adult guidelines recommend lower cut-off points. Therefore, we adopted the criterion from the International Diabetes Federation definition, which suggests high glucose levels as values $\geq 100 \mathrm{mmol} / \mathrm{l}^{(19)}$. In addition, high levels of LDL-cholesterol were also studied and defined as values $\geq 130 \mathrm{mmol} / \mathrm{l}^{(20)}$. A clustering of two or more of the variables mentioned above was similarly evaluated.

\section{Data analyses}

As most of the variables presented an abnormal distribution, medians and their interquartile ranges were used for the description of the study population by sex, and difference between these groups was estimated via the Mann-Whitney $U$ test. Values of WC and W-HtR were evaluated as age- and sex-specific quartiles. In each sex, Poisson regressions were performed to assess associations of highest quartiles of WC and W-HtR with MetS components and high LDL-cholesterol and with the fact of having two or more of these abnormalities. Each association was adjusted for the highest quartiles (also age- and sex-specific) of each trunk skinfold and BMI in separated models. Additional adjustment for age (continuous) was also evaluated. However, this covariate did not modify the effect estimates from unadjusted and adjusted models, presumably due to stratification by age in quartiles of WC, W-HtR, trunk skinfolds and BMI. All the analyses were processed using STATA 8.0 software (Statistics/Data Analysis, Stata Corp.).

\section{Results}

Study variables are described by sex in Table 1. Boys had higher values of WC and W-HtR, as well as higher prevalence of high fasting glucose and blood pressure. The prevalence of high levels of TAG and values of all the skinfold thickness measurements were higher in girls. There were no differences by sex regarding the prevalence of the cluster of abnormalities $(\geq 2)$ or overweight/obesity. An additional description of the study variables by age groups is shown in online Supplementary Table S1. Overall, the number of male and female adolescents in each age group was comparable. All the biochemical variables tended to decrease across age groups, whereas blood pressure and all the anthropometrical variables tended to increase with age.

The highest quartile of $\mathrm{WC}$ ( $v$. the other quartiles) was positively associated with high levels of TAG in all the adjustment models for both sexes (Table 2), and with high blood pressure in female adolescents. In girls, having at least two abnormalities was significantly associated with high WC before and after adjusting for each trunk's skinfold but not when adjusting for BMI. In boys, significant associations between high WC and high fasting glucose and low HDL-cholesterol were no longer significant in most of the adjustments for adiposity markers (Table 2). In girls, a significant association between high WC and low HDL-cholesterol was attenuated when SS or BMI scores were covariates in the regression models. Unexpectedly high WC became inversely associated with high fasting glucose in the SS-adjusted model and with high LDL-cholesterol in the BMI-adjusted model (Table 2).

The highest quartile of $\mathrm{W}-\mathrm{HtR}$ ( $v$. the other quartiles) was positively and significantly associated with high levels of TAG, despite adjustments for trunk's skinfolds and BMI in girls, whereas in boys this association was attenuated after adjustments, except in the SIS-adjusted model (Table 3). In both sexes, a significant relationship between having at least two abnormalities and high W-HtR was lost after adjusting for SS, SIS or BMI. In girls, an initial significant association between high W-HtR and low HDL-cholesterol did not remain significant after further adjustment for other adiposity markers (Table 3).

\section{Discussion}

In the present study, we evaluated the association between WC and W-HtR and cardiovascular risk factors. In addition, we 
Table 1. Description of the study population

(Medians and their interquartile ranges, number of subjects and percentages)

\begin{tabular}{|c|c|c|c|c|c|}
\hline & \multicolumn{2}{|c|}{ Boys } & \multicolumn{2}{|c|}{ Girls } & \multirow[b]{2}{*}{$P$} \\
\hline & $n$ & $\%$ & $n$ & $\%$ & \\
\hline$n$ & 831 & & 841 & & \\
\hline \multicolumn{6}{|l|}{ Age (years) } \\
\hline Median & \multicolumn{2}{|c|}{$14 \cdot 2$} & \multirow{2}{*}{\multicolumn{2}{|c|}{$\begin{array}{c}13 \cdot 9 \\
12 \cdot 3-16\end{array}$}} & 0.120 \\
\hline Interquartile range & \multicolumn{2}{|c|}{$12 \cdot 4-16$} & & & \\
\hline \multicolumn{6}{|l|}{ WC $(\mathrm{cm})$} \\
\hline Median & \multirow{2}{*}{\multicolumn{2}{|c|}{$\begin{array}{c}67 \\
62-71.5\end{array}$}} & \multirow{2}{*}{\multicolumn{2}{|c|}{$\begin{array}{c}63.5 \\
59-68\end{array}$}} & $<0.001$ \\
\hline Interquartile range & & & & & \\
\hline \multicolumn{6}{|l|}{ Waist:height ratio } \\
\hline Median & \multirow{2}{*}{\multicolumn{2}{|c|}{$\begin{array}{c}0.42 \\
0.40-0.44\end{array}$}} & \multirow{2}{*}{\multicolumn{2}{|c|}{$\begin{array}{c}0.41 \\
0.39-0.44\end{array}$}} & $<0.001$ \\
\hline Interquartile range & & & & & \\
\hline \multicolumn{6}{|c|}{ Metabolic syndrome components and high LDL-cholesterol } \\
\hline Glucose $\geq 100 \mathrm{mmol} / \mathrm{l}$ & 50 & $6 \cdot 0$ & 23 & $2 \cdot 7$ & 0.001 \\
\hline $\mathrm{HDL}$-cholesterol $\leq 40 \mathrm{mmol} / \mathrm{l}$ & 256 & $30 \cdot 8$ & 245 & $29 \cdot 1$ & 0.455 \\
\hline $\mathrm{TAG} \geq 110 \mathrm{mmol} / \mathrm{l}$ & 140 & $16 \cdot 8$ & 183 & $21 \cdot 8$ & 0.011 \\
\hline SBP and/or DBP $\geq 90$ th percentile & 103 & $12 \cdot 4$ & 33 & 3.9 & $<0.001$ \\
\hline LDL-cholesterol $\geq 130 \mathrm{mmol} / \mathrm{l}$ & 89 & $10 \cdot 7$ & 142 & $16 \cdot 9$ & $<0.001$ \\
\hline$\geq 2$ abnormalities & 144 & $17 \cdot 3$ & 153 & $18 \cdot 2$ & 0.644 \\
\hline \multicolumn{6}{|l|}{ Skinfold thickness } \\
\hline \multicolumn{6}{|l|}{ Subscapular (cm) } \\
\hline Median & \multirow{2}{*}{\multicolumn{2}{|c|}{$\begin{array}{c}9.5 \\
7.0-12.0\end{array}$}} & \multirow{2}{*}{\multicolumn{2}{|c|}{$\begin{array}{c}13 \\
10-17\end{array}$}} & $<0.001$ \\
\hline Interquartile range & & & & & \\
\hline \multicolumn{6}{|l|}{ Abdominal $(\mathrm{cm})$} \\
\hline Median & \multirow{2}{*}{\multicolumn{2}{|c|}{$\begin{array}{c}12 \\
9 \cdot 0-19\end{array}$}} & \multirow{2}{*}{\multicolumn{2}{|c|}{$\begin{array}{c}20 \\
15-25\end{array}$}} & $<0.001$ \\
\hline Interquartile range & & & & & \\
\hline \multicolumn{6}{|l|}{ Supra-iliac $(\mathrm{cm})$} \\
\hline Median & \multirow{2}{*}{\multicolumn{2}{|c|}{$\begin{array}{c}9 \cdot 0 \\
7 \cdot 0-15\end{array}$}} & \multirow{2}{*}{\multicolumn{2}{|c|}{$\begin{array}{c}15 \\
10-21\end{array}$}} & $<0.001$ \\
\hline Interquartile range & & & & & \\
\hline \multicolumn{6}{|l|}{ Overweight/obesity } \\
\hline $\mathrm{BMI}>85$ th percentile & 123 & 14.8 & 120 & $14 \cdot 3$ & 0.757 \\
\hline
\end{tabular}

WC, waist circumference; SBP, systolic blood pressure; DBP, diastolic blood pressure.

assessed whether these associations were independent of located subcutaneous adiposity and BMI. High WC values were found to be consistently and independently associated with high TAG levels in both sexes, and with high blood pressure specifically in female adolescents. The W-HtR was scarcely associated with MetS components, although it was independently associated with high TAG levels in female adolescents.

WC - but not W-HtR - was significantly and independently associated with high blood pressure in our study, and previous studies have presented conflicting results. Mirmiran et al. ${ }^{(21)}$ reached similar conclusions in 134 Iranian adolescents (10-18 years old). Moreover, two studies with Mexican and Dutch children reported associations with both adiposity markers, but WC was better associated with high blood pressure than $\mathrm{W}-\mathrm{HtR}^{(22,23)}$. In addition, W-HtR was deemed unsuitable as a screening tool for high blood pressure in German adolescents aged 11-17 years ${ }^{(24)}$, and Bailey et al. ${ }^{(25)}$ did not find any association between WC and W-HtR and SBP in 234 British children aged 10-19 years. Likewise, these associations have also been inconclusive in adults. For instance, although $\mathrm{Li}$ et $a l .{ }^{(26)}$ and Park et $a l .{ }^{(27)}$ found a stronger association of blood pressure with W-HtR than with WC in Asian adult populations, Valenzuela and Bustos reported comparable associations with both adiposity markers in young Chilean adults ${ }^{(28)}$.

High WC values were found to be consistently and independently associated with high levels of TAG in both sexes. This finding is in line with studies by Sijtsma et $a l .^{(23)}$ and
Harrington et al. ${ }^{(29)}$, who reported significant positive associations between WC and TAG in pre-pubertal and pubertal children. This finding was also related to WC as a good predictive factor of hypertriglyceridaemia in a sample of 41087 adults $^{(30)}$. In this study, we have extended the knowledge about this relationship by finding it to be independent of other adiposity markers.

Previous studies have reported associations between high levels of TAG and W-HtR in paediatric populations. Graves et $a l^{(31)}$ reported a prospective association between $\mathrm{W}-\mathrm{HtR}$ in childhood and cardiometabolic outcomes in adolescents, with an increased risk in boys. A cross-sectional study by BalasNakash et $a l .{ }^{(22)}$ describes a similar finding, adjusting for age, sex, physical activity, hours per week of television, video games or computer, energy consumption and percentage of dietary lipids. In contrast, this association was NS in an unadjusted analysis carried out by Feliciano Pereira et al. ${ }^{(32)}$, and in another study WC was found to be more strongly related to the levels of TAG than W-HtR ${ }^{(21)}$, adjusting for sex and physical activity. Our study, with regard to the relationship between W-HtR and high TAG levels, is in line with most of the studies mentioned above based on associations not adjusted for other adiposity markers. However, a sex-specific relationship was evident, as only in the female adolescents the association remained significant, despite adjustment for skinfolds or BMI.

High LDL-cholesterol was the abnormality less associated with WC and W-HtR in the adolescents from our study, even in 
Table 2. Prevalence ratios for metabolic syndrome components and high LDL-cholesterol by age- and sex-specific quartiles (Q) of waist circumference (highest quartile $v$. quartiles $1-3$ ) in the adolescents (Prevalence ratios and $95 \%$ confidence intervals)

\begin{tabular}{|c|c|c|c|c|c|c|c|c|c|c|c|}
\hline & \multirow[b]{2}{*}{ Q1-Q3 } & \multicolumn{2}{|c|}{ Q4 unadjusted } & \multicolumn{2}{|c|}{ Q4 adjusted for Q4 of AS } & \multicolumn{2}{|c|}{ Q4 adjusted for Q4 of SS } & \multicolumn{2}{|c|}{ Q4 adjusted for Q4 of SIS } & \multicolumn{2}{|c|}{ Q4 adjusted for Q4 of BMI } \\
\hline & & Prevalence ratio & $95 \% \mathrm{Cl}$ & Prevalence ratio & $95 \% \mathrm{Cl}$ & Prevalence ratio & $95 \% \mathrm{Cl}$ & Prevalence ratio & $95 \% \mathrm{Cl}$ & Prevalence ratio & $95 \% \mathrm{Cl}$ \\
\hline \multicolumn{12}{|l|}{ Boys } \\
\hline High fasting glucose & 1.0 & $1.87^{\star}$ & $1.08,3.24$ & 1.58 & $0.77,3.23$ & $2.00^{*}$ & $1.03,3.89$ & 1.75 & $0.88,3.48$ & $1 \cdot 11$ & $0.41,2.99$ \\
\hline Low HDL-cholesterol & 1.0 & $1.33^{\star}$ & $1.07,1.65$ & $1 \cdot 17$ & $0.90,1.53$ & $1 \cdot 11$ & $0.83,1.47$ & 1.19 & $0.90,1.56$ & 1.21 & $0.89,1.65$ \\
\hline High LDL-cholesterol & 1.0 & 1.12 & $0.72,1.75$ & 0.77 & $0.44,1.34$ & 0.92 & $0.53,1.62$ & 1.01 & $0.62,1.65$ & 1.10 & $0.60,2.01$ \\
\hline High TAG & 1.0 & $2.57^{\star}$ & $1.91,3.44$ & $1.87^{\star}$ & $1 \cdot 26,2 \cdot 77$ & $1.82^{*}$ & $1 \cdot 19,2 \cdot 78$ & $2.07^{\star}$ & $1 \cdot 39,3 \cdot 10$ & $1.95^{\star}$ & $1 \cdot 16,3 \cdot 27$ \\
\hline High blood pressure & 1.0 & $1.64^{*}$ & $1.12,2.38$ & $1.88^{\star}$ & $1.15,3.08$ & 1.38 & $0.87,2.21$ & 1.54 & $0.95,2.48$ & 0.91 & $0.56,1.47$ \\
\hline$\geq 2$ abnormalities & 1.0 & $2 \cdot 05^{\star}$ & $1.53,2.76$ & 1.44 & $0 \cdot 99,2 \cdot 10$ & 1.39 & $0.94,2.06$ & $1 \cdot 60^{*}$ & $1 \cdot 09,2 \cdot 33$ & 1.28 & $0.82,1.99$ \\
\hline \multicolumn{12}{|l|}{ Girls } \\
\hline High fasting glucose & 1.0 & 0.43 & $0.13,1.44$ & 0.39 & $0.10,1.49$ & $0.23^{*}$ & $0.05,0.88$ & 0.26 & $0.07,1.02$ & 0.58 & $0.13,2.42$ \\
\hline Low HDL-cholesterol & 1.0 & $1.59^{*}$ & $1.28,1.96$ & $1.37^{\star}$ & $1.01,1.70$ & $1 \cdot 16$ & $0.90,1.51$ & $1.33^{\star}$ & $1.04,1.70$ & $1 \cdot 14$ & $0.86,1.52$ \\
\hline High LDL-cholesterol & 1.0 & 1.09 & $0.78,1.53$ & 0.96 & $0.64,1.42$ & 0.92 & $0.62,1.35$ & 1.09 & $0.73,1.62$ & $0.61^{*}$ & $0.40,0.93$ \\
\hline High TAG & 1.0 & $1.92^{\star}$ & $1.49,2.47$ & $1.58^{\star}$ & $1 \cdot 16,2 \cdot 14$ & $1.57^{\star}$ & $1 \cdot 16,2 \cdot 12$ & $1.61^{*}$ & $1 \cdot 20,2 \cdot 16$ & $1.52^{*}$ & $1 \cdot 08,2 \cdot 13$ \\
\hline High blood pressure & 1.0 & $3.07^{\star}$ & $1.58,5.98$ & $2 \cdot 50^{\star}$ & $1.11,5.59$ & $2 \cdot 90^{\star}$ & $1.45,5.79$ & $3.05^{\star}$ & $1.37,6.79$ & $3.47^{\star}$ & $1.49,8.08$ \\
\hline$\geq 2$ abnormalities & 1.0 & $1.97^{\star}$ & $1.48,2.61$ & $1.58^{\star}$ & $1 \cdot 11,2 \cdot 24$ & $1.49^{*}$ & $1.05,2.10$ & $1.55^{\star}$ & $1 \cdot 10,2 \cdot 18$ & 1.35 & $0.93,1.97$ \\
\hline
\end{tabular}

AS, abdominal skinfold; SS, subscapular skinfold; SIS, supra-iliac skinfold.

* Significant associations $(P<0.05)$.

Table 3. Prevalence ratios for metabolic syndrome components and high LDL-cholesterol by age- and sex-specific quartiles (Q) of waist:height ratio (highest quartile $v$. quartiles $1-3)$ in adolescents (Prevalence ratios and $95 \%$ confidence intervals)

\begin{tabular}{|c|c|c|c|c|c|c|c|c|c|c|c|}
\hline & \multirow[b]{2}{*}{ Q1-Q3 } & \multicolumn{2}{|c|}{ Q4 unadjusted } & \multicolumn{2}{|c|}{ Q4 adjusted for Q4 of AS } & \multicolumn{2}{|c|}{ Q4 adjusted for Q4 of SS } & \multicolumn{2}{|c|}{ Q4 adjusted for Q4 of SIS } & \multicolumn{2}{|c|}{ Q4 adjusted for Q4 of BMI } \\
\hline & & Prevalence ratio & $95 \% \mathrm{Cl}$ & Prevalence ratio & $95 \% \mathrm{Cl}$ & Prevalence ratio & $95 \% \mathrm{Cl}$ & Prevalence ratio & $95 \% \mathrm{Cl}$ & Prevalence ratio & $95 \% \mathrm{Cl}$ \\
\hline \multicolumn{12}{|l|}{ Boys } \\
\hline High fasting glucose & $1 \cdot 0$ & 1.41 & $0.79,2.51$ & 1.04 & $0.51,2.11$ & 1.26 & $0.65,2.45$ & $1 \cdot 11$ & $0 \cdot 56,2 \cdot 21$ & 0.74 & $0.35,1.55$ \\
\hline Low HDL-cholesterol & $1 \cdot 0$ & 1.22 & $0.98,1.52$ & 1.04 & $0.80,1.36$ & 1.00 & $0.77,1.30$ & 1.03 & $0.78,1.36$ & 1.04 & $0.78,1.38$ \\
\hline High LDL-cholesterol & 1.0 & 1.24 & $0.80,1.91$ & 0.94 & $0.53,1.65$ & $1 \cdot 11$ & $0.63,1.95$ & $1 \cdot 18$ & $0.71,1.95$ & $1 \cdot 30$ & $0 \cdot 74,2 \cdot 27$ \\
\hline High TAG & $1 \cdot 0$ & $2 \cdot 13^{*}$ & $1 \cdot 58,2 \cdot 87$ & 1.42 & $0.97,2.08$ & 1.40 & $0.96,2.04$ & $1.51^{*}$ & $1 \cdot 01,2 \cdot 28$ & 1.37 & $0.87,2.14$ \\
\hline High blood pressure & 1.0 & 1.42 & $0.96,2.08$ & 1.47 & $0.90,2.39$ & $1 \cdot 13$ & $0.73,1.73$ & 1.22 & $0.77,1.93$ & 0.79 & $0.47,1.30$ \\
\hline$\geq 2$ abnormalities & 1.0 & $1.65^{*}$ & $1 \cdot 22,2 \cdot 23$ & 1.06 & $0.73,1.55$ & 1.05 & $0.72,1.51$ & $1 \cdot 11$ & $0.74,1.65$ & 0.92 & $0.60,1.39$ \\
\hline \multicolumn{12}{|l|}{ Girls } \\
\hline High fasting glucose & 1.0 & 0.63 & $0.21,1.83$ & 0.62 & $0.16,2.39$ & 0.36 & $0.12,1.04$ & 0.41 & $0.14,1 \cdot 15$ & 0.94 & $0.27,3.19$ \\
\hline Low HDL-cholesterol & $1 \cdot 0$ & $1.59^{*}$ & $1.24,1.90$ & $1 \cdot 24$ & $0.95,1.62$ & $1 \cdot 11$ & $0.86,1.43$ & 1.26 & $0.98,1.63$ & $1 \cdot 14$ & $0.87,1.48$ \\
\hline High LDL-cholesterol & $1 \cdot 0$ & $1 \cdot 13$ & $0.81,1.58$ & 1.00 & $0.68,1.46$ & 0.96 & $0.67,1.39$ & $1 \cdot 14$ & $0.78,1.68$ & 0.74 & $0.51,1.08$ \\
\hline High TAG & 1.0 & $1.99^{*}$ & $1.55,2.56$ & $1.66^{*}$ & $1 \cdot 20,2 \cdot 28$ & $1.65^{\star}$ & $1 \cdot 23,2 \cdot 25$ & $1.69^{*}$ & $1 \cdot 25,2 \cdot 28$ & $1.62^{*}$ & $1 \cdot 19,2 \cdot 23$ \\
\hline High blood pressure & $1 \cdot 0$ & 1.95 & $0.98,3.85$ & 1.29 & $0.65,2.53$ & 1.55 & $0.79,3.02$ & 1.68 & $0.78,3.63$ & 1.53 & $0.73,3.22$ \\
\hline$\geq 2$ abnormalities & $1 \cdot 0$ & $1.83^{*}$ & $1 \cdot 37,2 \cdot 44$ & $1.41^{*}$ & $1 \cdot 00,2 \cdot 01$ & 1.35 & $0.97,1.88$ & 1.39 & $0.99,1.95$ & 1.26 & $0.90,1.77$ \\
\hline
\end{tabular}

AS, abdominal skinfold; SS, subscapular skinfold; SIS, supra-iliac skinfold.

* Significant associations $(P<0.05)$. 
unadjusted associations. With regard to this relationship, there are conflicting results in previous studies as well. In pre-pubertal children, Sijtsma et al. did not find correlations between WC, W-HtR and LDL-cholesterol, whereas Hara et al. ${ }^{(33)}$ reported significant association in boys and girls aged 9-13 years. Recently, White and $\mathrm{Jago}^{(34)}$ found a strong and significant association between the change in WC and the change in LDL-cholesterol levels in a cohort of 617 female adolescents during the 10 years of follow-up. On the other hand, LDL-cholesterol was the risk marker less associated with WC in a large epidemiological study in adults ${ }^{(35)}$.

The unexpected inverse associations of WC with high fasting glucose levels in the SS-adjusted model and with high LDL-cholesterol in the BMI-adjusted model could be chance findings. This is due to the fact that these associations were not consistently significant throughout the rest of the adjustment models. Alternatively, it is also possible that some confounder not evaluated in this study might have had an influence on these findings.

Despite adjustments for other adiposity markers attenuating some relationships, our general finding is that WC itself is a better indicator of cardiometabolic risk than W-HtR, especially based on vascular and lipid risk factors. In other words, our results do not support W-HtR as a relevant adiposity marker related to cardiometabolic risk in adolescence. This agrees with a body of literature in young children and adults in which W-HtR was not found to be better associated with cardiometabolic risk factors or MetS than $\mathrm{WC}^{(23,36)}$. In addition, the conflicting reports from studies mentioned above regarding associations with blood pressure and LDL-cholesterol could be explained by differences in statistical power, methodological approaches (e.g. adjustments, laboratory tests) and populations (e.g. young children/adolescents, ethnicity). Multicentre studies are warranted for a better interpretation of the associations between WC, W-HtR and cardiometabolic risk markers.

Data on pubertal changes, ethnicity and physical activity were not available for this analysis and these variables would have allowed for more robust adjustments. However, the age variable is strongly related to pubertal changes, and the stratification by age that we performed for WC and W-HtR may have decreased the bias of not adjusting for pubertal development. Further, adjustments for each trunk's skinfolds in the present study allowed for obtaining a more precise independence profile for the evaluated associations, an approach that had not been considered in previous studies.

In conclusion, the findings of this study suggest that abdominal adiposity itself would be a better indicator of cardiometabolic risk in adolescents than abdominal adiposity regarding height. This observation does not support W-HtR as a relevant adiposity marker for cardiovascular and metabolic risks in adolescence.

\section{Acknowledgements}

The authors thank Dr Daniel Herrera-Kelly and Dr Paul Kawale for their support on English language grammar and style.

This work was funded by a grant from the Colombian Administrative Department for Development and Science Technology (COLCIENCIAS).
R. A. A. Z. conceived the research question and wrote the manuscript. C. A. d. P. coordinated field work, researched data and edited the manuscript. M. F. S. O. conceived the study design, analysed the data and wrote the manuscript.

The authors declare no conflicts of interest.

\section{Supplementary Material}

For supplementary material/s referred to in this article, please visit http://dx.doi.org/10.1017/S0007114515002275

\section{References}

1. Yarnell JW, Patterson CC, Thomas HF, et al. (2001) Central obesity: predictive value of skinfold measurements for subsequent ischaemic heart disease at 14 years follow-up in the Caerphilly Study. Int J Obes Relat Metab Disord 25, 1546-1549.

2. Schulze MB, Heidemann C, Schienkiewitz A, et al. (2006) Comparison of anthropometric characteristics in predicting the incidence of type 2 diabetes in the EPIC-Potsdam study. Diabetes Care 29, 1921-1923.

3. Freedman DS, Kahn HS, Mei Z, et al. (2007) Relation of body mass index and waist-to-height ratio to cardiovascular disease risk factors in children and adolescents: the Bogalusa Heart Study. Am J Clin Nutr 86, 33-40.

4. Lyon CJ, Law RE, Hsue L, et al. (2003) Minireview: adiposity, inflammation and atherogenesis. Endocrinology 144, 2195-2200.

5. Mokha JS, Srinivasan SR, DasMahapatra P, et al. (2010) Utility of waist-to-height ratio in assessing the status of central obesity and related cardiometabolic risk profile among normal weight and overweight/obese children: the Bogalusa Heart Study. BMC Pediatr 10, 73-79.

6. Savva SC, Lamnisos D \& Kafatos AG (2012) Predicting cardiometabolic risk: waist-to-height ratio or BMI: a meta-analysis. Diabetes Metab Syndr Obes 24, 403-419.

7. Ashwell M, Gunn P \& Gibson S (2012) Waist-to-height ratio is a better screening tool than waist circumference and BMI for adult cardiometabolic risk factors: systematic review and meta-analysis. Obes Rev 13, 275-286.

8. Browning LM, Hsieh SD \& Ashwell M (2010) A systematic review of waist-to-height ratio as a screening tool for the prediction of cardiovascular disease and diabetes: 0.5 could be a suitable global boundary value. Nutr Res Rev 23, 247-269.

9. Ashwell M \& Hsieh SD (2005) Six reasons why the waist-toheight ratio is a rapid and effective global indicator for health risks of obesity and how its use could simplify the international public health message on obesity. Int J Food Sci Nutr 56, 303-307.

10 Gracia B, de Plata C, Méndez F, et al. (2005) Evaluation of early manifestations of chronic no transmitted diseases risk in school population in Cali - Colombia. Arch Latinoam Nutr $\mathbf{5 5}$, 267-278.

11 Friedewald WT, Levy RI \& Fredrickson DS (1972) Estimation of the concentration of low-density lipoprotein cholesterol in plasma without use of the preparative ultracentrifuge. Clin Chem 18, 499-502.

12. Franklin SS, Gustin W, Wong ND, et al. (1997) Hemodynamic patterns of age-related changes in blood pressure. The Framingham Heart Study. Circulation 96, 308-315.

13. Lohman TG, Roche AF \& Martorell R (1988) Antbropometric Standardization Reference Manual. Champaign, IL: Human Kinetics Books. 
14. Keys A, Fidanza F, Karvonen MJ, et al. (1972) Indices of relative weight and obesity. J Chron Dis 25, 329-343.

15. Lohman TG (1986) Applicability of body composition techniques and constants for children and youth. Exerc Sport Sci Rev 14, 325-357.

16. Cook S, Weitzman M, Auinger P, et al. (2003) Prevalence of a metabolic syndrome phenotype in adolescents: findings from the third National Health and Nutrition Examination Survey, 1988-1994. Arch Pediatr Adolesc Med 157, 821-827.

17. Costa RF, Santos NS, Goldraich NP, et al. (2012) Metabolic syndrome in obese adolescents: a comparison of three different diagnostic criteria. J Pediatr (Rio J) 88, 303-309.

18. National Heart, Lung, and Blood Institute (2004) Blood pressure tables for children and adolescent from the Fourth Report on the diagnosis, evaluation and treatment of high blood pressure in children and adolescents. http://www.nhlbi.nih.gov/guidelines/ hypertension/child_tbl.pdf (accessed June 2014).

19. Zimmet P, Alberti KG, Kaufman F, et al. (2007) The metabolic syndrome in children and adolescents - an IDF consensus report. Pediatr Diabetes 8, 299-306.

20. Kit BK, Carroll MD, Lacher DA, et al. (2012) Trends in serum lipids among US youths aged 6 to 19 years, 1988-2010. JAMA 308, 591-600.

21. Mirmiran P, Rezaei M, Asghari G, et al. (2014) Association of metabolic syndrome with body fat percent, anthropometric indices in 10 to 18 year old adolescents. Iran J Public Health 43, 193-201.

22. Balas-Nakash M, Villanueva-Quintana A, Tawil-Dayan S, et al. (2008) Pilot study to identify anthropometric indices associated with metabolic syndrome risk markers in school-aged Mexican children. Bol Med Hosp Infant Mex 65, 100-109.

23. Sijtsma A, Bocca G, L'Abée C, et al. (2013) Waist-to-height ratio, waist circumference and BMI as indicators of percentage fat mass and cardiometabolic risk factors in children aged 3-7 years. Clin Nutr 33, 311-315.

24. Kromeyer-Hauschild K, Neuhauser H, Schaffrath Rosario A, et al. (2013) Abdominal obesity in German adolescents defined by waist-to-height ratio and its association to elevated blood pressure: the KiGGS study. Obes Facts 6, 165-175.

25. Bailey DP, Savory LA, Denton SJ, et al. (2013) The hypertriglyceridemic waist, waist-to-height ratio, and cardiometabolic risk. J Pediatr 162, 746-752.
26. Li WC, Chen IC, Chang YC, et al. (2013) Waist-to-height ratio, waist circumference, and body mass index as indices of cardiometabolic risk among 36,642 Taiwanese adults. Eur J Nutr 52, 57-65.

27. Park SH, Choi SJ, Lee KS, et al. (2009) Waist circumference and waist-to-height ratio as predictors of cardiovascular disease risk in Korean adults. Circ J 73, 1643-1650.

28. Valenzuela K \& Bustos P (2012) Índice cintura estatura como predictor de riesgo de hipertensión arterial en población adulta joven: ¿Es mejor indicador que la circunferencia de cintura? (Waist:height ratio as a predictor of risk of hypertension in young adults: is it a better indicator that waist circumference?). Arch Latinoam Nutr 62, 220-226.

29. Harrington DM, Staiano AE, Broyles ST, et al. (2013) Waist circumference measurement site does not affect relationships with visceral adiposity and cardiometabolic risk factors in children. Pediatr Obes 8, 199-206.

30. Du SM, Ma GS, Li YP, et al. (2010) Relationship of body mass index, waist circumference and cardiovascular risk factors in Chinese adult. Biomed Environ Sci 23, 92-101.

31. Graves L, Garnett SP, Cowell CT, et al. (2013) Waist-to-height ratio and cardiometabolic risk factors in adolescence: findings from a prospective birth cohort. Pediatr Obes 25, 327-338.

32. Feliciano Pereira P, Serrano HM, Queiroz Carvalho G, et al. (2011) Waist and waist-to-height ratio: useful to identify the metabolic risk of female adolescents? Rev Paul Pediatr 29, 372-377.

33. Hara M, Saitou E, Iwata F, et al. (2002) Waist-to-height ratio is the best predictor of cardiovascular disease risk factors in Japanese schoolchildren. J Atheroscler Thromb 9 , $127-132$.

34. White J \& Jago R (2013) Fat distribution, physical activity and cardiovascular risk among adolescent girls. Nutr Metab Cardiovasc Dis 23, 1891-1895.

35. Bennasar-Veny M, Lopez-Gonzalez AA, Tauler P, et al. (2013) Body adiposity index and cardiovascular health risk factors in Caucasians: a comparison with the body mass index and others. PLOS ONE 8, e0122985.

36. Bener A, Yousafzai MT, Darwish S, et al. (2013) Obesity index that better predict metabolic syndrome: body mass index, waist circumference, waist hip ratio, or waist height ratio. J Obes 2013, 269038. 